$$
\begin{aligned}
& \text { CONF-961073*2 } \\
& \text { ANL/TD/CP_-90094. }
\end{aligned}
$$

\title{
Laser-Based Characterization and Decontamination of Contaminated Facilities
}

\author{
K. H. Leong, B. V. Hunter, J. E. Grace and M. J. Pellin \\ Argonne National Laboratory \\ 9700 S. Cass Ave., BIdg 207 \\ Argonne, Illinois 60439 \\ USA
}
H. F. Leidich and T. R. Kugler
Lumonics Corporation
19776 Haggerty Road
Livonia, Michigan 48152
USA

\begin{abstract}
The submitted manuscript has been authorized by a contractor of the $U$. S. Government under contract No. W-31-109-ENG-38. Accordingly, the U. S. Government retains a non-exclusive, royalty-free license to publish or reproduce the published form of this contribution, or allow others to do so, for U. S. Government purposes.
\end{abstract}

\section{$\underline{\text { Abstract }}$}

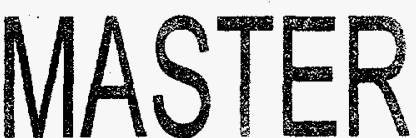

This study examines the application of laser ablation to the characterization and decontamination of painted and unpainted concrete and metal surfaces that are typical of many facilities within the United States Department of Energy complex. The utility of this promising technology is reviewed and the essential requirements for efficient ablation extracted. Recent data obtained on the ablation of painted steel surfaces and concrete are presented. The effects of beam irradiance, ablation speed and efficiency, and characteristics of the aerosol effluent are discussed. Characterization of the ablated components of the surface offers the ability of concurrent determination of the level of contamination. This concept can be applied online where the ablation endpoint can be determined. A conceptual system for the characterization and decontamination of surfaces is proposed.

\section{Introduction}

With the end of the Cold War and the reduction in nuclear weapons production, and research and development in nuclear power, the U.S. Department of Energy (DOE) has initiated deactivation, decontamination and decommissioning of a number of facilities. Many of these older facilities were developed and used when the hazards related to radiation exposure were not fully understood. Consequently, many areas in such facilities have varying degrees of radiological contamination. Estimates of contaminated concrete within these DOE complexes are in the range of $10^{8}$ to $10^{9} \mathrm{ft}^{2}$ with volumes of $10^{6}$ to $10^{7} \mathrm{ft}^{3} 1$.

Many techniques have been tested or proposed for cleaning contaminated surfaces 2. Some are as simple as soap and water. Others remove contaminants by use of chemicals, sandblasting, ablation with frozen $\mathrm{CO}_{2}$ pellets, or high-pressure/abrasive water jets. These chemical and inertial-based techniques are often effective, but have many drawbacks: they often generate mixed 


\section{DISCLAIMER}

Portions of this document may be illegible in electronic image products. Images are produced from the best available original document. 


\section{DISCLAIMER}

This report was prepared as an account of work sponsored by an agency of the United States Government. Neither the United States Government nor any agency thereof, nor any of their employees, makes any warranty, express or implied, or assumes any legal liability or responsibility for the accuracy, completeness, or usefulness of any information, apparatus, product, or process disclosed, or represents that its use would not infringe privately owned rights. Reference herein to any specific commercial product, process, or service by trade name, trademark, manufacturer, or otherwise does not necessarily constitute or imply its endorsement, recommendation, or favoring by the United States Government or any agency thereof. The views and opinions of authors expressed herein do not necessarily state or reflect those of the United States Government or any agency thereof. 
wastes and they can damage the surfaces. Chemical or inertia-based methods frequently drive some fraction of the contaminants deeper into the material, particularly if the material is porous. Laser ablation avoids these difficulties by vaporizing the contaminated surface to yield a very small volume of contaminated waste that can be captured 3,4. The surface can be protected from damage by precise control of the laser energy, and the vaporization process does not drive the contaminants deeper into the material. This technology is particularly attractive in that an appropriately chosen beam can be delivered by a fiber optic cable and manipulated by a robot 5 . Thus, we have a flexible tool for cutting as well as decontamination.

The CP-5 Reactor facility at Argonne National Laboratory has been selected by DOE as a D\&D large scale demonstration project. It offers the opportunity for the introduction, demonstration, and evaluation of emerging technologies in a prototypic low level contaminated environment. Argonne is collaborating with Lumonics Corporation to test the efficacy of a fiber delivered high power Nd:YAG laser beam in the removal of contaminated surfaces of painted and unpainted concrete and steel structures. Concurrent containment of the effluent produced by laser ablation of the surface is also investigated. This technology may be suitable for demonstration at CP-5.

The results of laboratory tests carried out at both Argonne's Laser Applications Laboratory and Lumonics Corporation on the laser ablation of painted steel surfaces and concrete will be presented. Parameters such as irradiance, ablation speed and efficiency and characterization of the aerosol effluent will be discussed.

\section{Laser Ablation of Surfaces}

Numerous engineering studies have been carried out using a variety of laser types and wavelengths for removal of coatings and contaminated surfaces 3,4,6-9. Both continuous wave (cw) and pulsed $\mathrm{CO}_{2}$ and $\mathrm{Nd}$ :YAG lasers and excimer lasers have been used. Ablation rates were generally found to increase with peak power and/or the absorptivity of the coating at the particular wavelength of the irradiating laser beam. The peak power varied among the types of lasers used, with short pulsed lasers producing the highest ablation rates. The effectiveness of various beam modes and powers depended on the characteristics of the surface treated. Paints and non-metallic or non-ceramic coatings can be effectively removed by both $\mathrm{cw}$ and pulsed lasers. The relatively longer interaction time of $\mathrm{cw}$ beams results in thermal conduction. For metals, melting and thermal distortion result, permitting the penetration of contaminants further into the substrate 4 . High peak irradiance pulsed beams tend to cause much less damage to the underlying substrate than $\mathrm{cw}$ beams, due to an enhanced adiabicity associated with the short time scale and a secondary interaction between the vapor/aerosol plume and the surface. However, short pulsed beams with high peak power may cause some substrate damage due to ultrasonic and shock wave effects 9 . Substrate damage is a minor concern for decontamination compared to stripping paint from airplanes or bridges, or removing soot and grime from a painting or esthetic structure.

The above studies drew conclusions in regard to the effectiveness of particular lasers on specific surfaces without much consideration of the effects of beam irradiance regimes and the underlying ablation phenomena. For example, most paints have a substantially higher absorptivity for the $10.6 \mu \mathrm{m}$ infrared wavelength of the $\mathrm{CO}_{2}$ beam than the $1.06 \mu \mathrm{m}$ near-infrared wavelength of the Nd:YAG. For low irradiance, absorptivity is the controlling parameter, while for high irradiance, the beam intensity is sufficient to break down the material regardless of the absorptivity.

More recent studies indicate that the effects of wavelength absorptivity of the surface, thermal conductivity of both the coating and the substrate, acoustic effects, and cover gas are expected to have varying significance in different irradiance regimes 10,11. The design of an optimal laser ablation system, one that cleans or characterizes effectively while minimizing waste effluent and 
surface damage, requires a fundamental understanding of the ablation process. Consequently, a detailed study was initiated at Argonne to delineate the different processes occurring during laser ablation for both contaminant characterization and removal. The results of the study will facilitate pragmatic choices on cost effective methods of laser decontamination.

\section{Effluent Production and Characterization}

The interaction of a high power laser with a surface can produce a variety of effects that include localized heating, generation of acoustic or shock waves, vaporization, and plasma formation 12 . For the current application, the phenomena of concern are vaporization, interaction of the vapor with ambient gases and the laser beam, and the subsequent condensation and coagulation to form aerosol particles. In addition, some of the surface material may be directly aerosolized, and for some materials such as paint, combustion will also occur with some soot formation.

The laser beam-solid interaction can be segregated into different irradiance regimes 13. At relatively low irradiance, the absorptivity of the surface controls the energy transfer, and the pulse duration and thermal conductivity of the material control the thermal conduction. Melting and vaporization occur as the temperature of the material increases; however, melting is undesirable for effective decontamination as it can cause the contaminants to penetrate into the substrate 4 . Consequently, high irradiance is necessary to heat the surface rapidly and thereby minimize melting. At irradiance levels adequate to cause direct volatilization of the material, the conventional absorptivity of the surface at low irradiance levels is no longer a consideration 13. In addition, conduction of heat is minimized and the ablation and heat effects are localized. High irradiance can be achieved easily with short pulsed lasers, and the literature results are consistent with this expectation. At irradiance levels above $10^{6} \mathrm{~W} \mathrm{~cm}-2$, a plasma forms above the material being ablated, and attenuates the incident beam energy. Nevertheless, results on paint stripping on a concrete substrate show a monotonic increase in efficiency with irradiance 10 . Other high irradiance phenomena, such as shock waves may assist in removing the paint. In fact, the acoustic waves produced during laser ablation are quite audible.

At high irradiance $\left(>10^{6} \mathrm{~W} \mathrm{~cm}^{-2}\right)$, the dense plasma absorbs the laser beam energy and shields it from the surface. The energy is transferred to the surface in the form of energetic ions, shifting the overall laser-solid interaction from thermal to inertial. Above the ignition threshold, the plasma is responsible for essentially all of the surface ablation. This mode of energy deposition applies equally to any surface, regardless of composition.

The plasma-surface coupling is generally understood for ablation of elementally pure surfaces in vacuum. Variables such as ablation rate and depth, and many plasma properties such as pressure and temperature are well predicted by straightforward plasma theory 14 . However the presence of a backing gas greatly complicates matters. In general the gas limits the energy that can be delivered to the surface 15 , promotes condensation 16,17 , and can react with the target material to form new compounds, thus altering the chemical composition of the effluent 18 . The backing gas provides a degree of control over the ablation and condensation processes by removing the surface specificity of the interaction. The backing gas (e.g. $\mathrm{O}_{2}$ ) can also supply additional energy for ablation by causing exothermic reactions with the surface. These gas-mediated interaction modes, and their effects on the removal rate and the chemical and physical properties of the effluent needs to be better understood for the optimal application of laser ablation.

Characterization of hazardous aerosols produced by laser processing particularly with respect to polymers and plastics and organic and inorganic materials has been carried out 19,20. Most of the effort has been focused on the hazardous nature of the effluent produced and less on the aerosol 
size distributions. Aerosol characterization were mostly carried out on laser cutting with the general observation that the mass of the particles was concentrated in the sub-micron size range i.e. $<0.2 \mu \mathrm{m} 21,22$.

Argonne has recently characterized the aerosol resulting from the laser ablation of paint coatings on metals using a high power $(1.6 \mathrm{~kW})$ pulsed Nd:YAG laser with fiber-optic beam delivery ${ }^{9}$. The Nd:YAG laser, operating at $1064 \mathrm{~nm}$, is well suited for transmission through highpower optical fibers into hazardous or hard-to-access locations via a small, flexible cable. The laser beam is shaped and targeted on the surface by the output optics which may be mounted on a CNC motion system, such as a robotic arm or a 5-axis workstation. This concept is illustrated in Figure 1. The effluent collection system uses a shroud and suction to contain the particles generated by the ablation of the contaminated surface. The particles are passed through a HEPA filter to remove the hazardous aerosols. The design of the shroud is a key consideration in the effectiveness of the effluent collection and the efficiency of material removal. Various shrouds and variants were investigated to better understand the aerodynamics in the shroud so that constraints for an optimal design can be determined. It should be noted

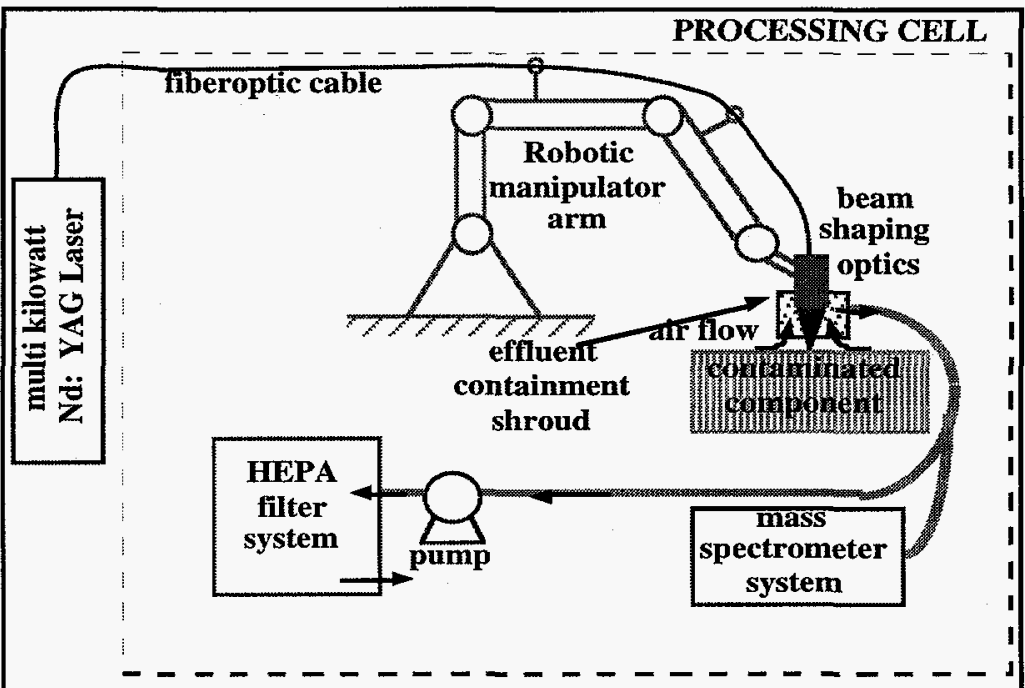

Figure 1. Schematic of a laser ablation system for decontamination and characterization of contaminated surfaces

that for decontamination applications, it is essential to contain all the effluent produced from the ablation process. In other non-critical applications, a suction hose on the side usually suffices. The shroud used to obtain the data discussed below is shown in Figure 2. Suction is by a fan-type pump and blower-type pump in series, providing a maximum flowrate of $1700 \mathrm{lpm}$ or $850 \mathrm{lpm}$ at a pressure of $3.7 \mathrm{kPa}\left(15\right.$ in $\left.\mathrm{H}_{2} \mathrm{O}\right)$. One or more of the 4 ports on the shroud can be used for suction. Part of the effluent flow can be diverted to a mass spectrometer system for contaminant analysis.

The effectiveness of the shroud was determined by using standard aerosol counting techniques to monitor the total number of particles inside and outside the shroud, and the size distributions of particles. This aerosol monitoring was one method used to assess the containment effectiveness of the shrouds. Additionally, based upon knowledge of the paint composition, massbalance measurements provided a second vehicle for determining collection efficiency. Painted surfaces were stripped during this portion of the project. The experimental setup used for some of these experiments is shown in Figure 2. High efficiency particulate air (HEPA) filters were used at all 4 ports of the shroud to collect the particulate mass produced during laser ablation of the paint.

Data was obtained for different flowrates and peak irradiance values from $0.94 \times 10^{4}$ to $3.9 \times 10^{4} \mathrm{~W} \mathrm{~cm}^{-2}$ by varying the pulse energy and the spot size. At irradiance levels $<3 \times 10^{4} \mathrm{~W}$ $\mathrm{cm}^{-2}$, the shroud aerodynamics strongly influences the efficiency of paint removal. The shroud dimensions, flow rates, and flow patterns can reduce the overall process efficiency by encouraging soot formation and redeposition. The soot was removed by an additional cleaning pass. It was possible to prevent the formation of a soot layer and increase the speed of the process by using a side jet as is frequently used in paint removal or other laser assisted processes. However, the high 
velocity jet prevented efficient containment of the aerosol. Beam irradiances $>3 \times 10^{4} \mathrm{~W} \mathrm{~cm}^{-2}$ prevented soot formation.

Adequate suction (300-850 lpm) ensured containment of the aerosol. By mass balance, $>99 \%$ of the paint was collected. The unaccounted mass consisted mostly of $>10$ $\mu \mathrm{m}$ particles that settled out or impacted on surfaces and uncertainties in the measurements of paint mass. The aerosol data showed that $>99.97 \%$ of the particles smaller than $10 \mu \mathrm{m}$ were collected. Particles $<10 \mu \mathrm{m}$ are

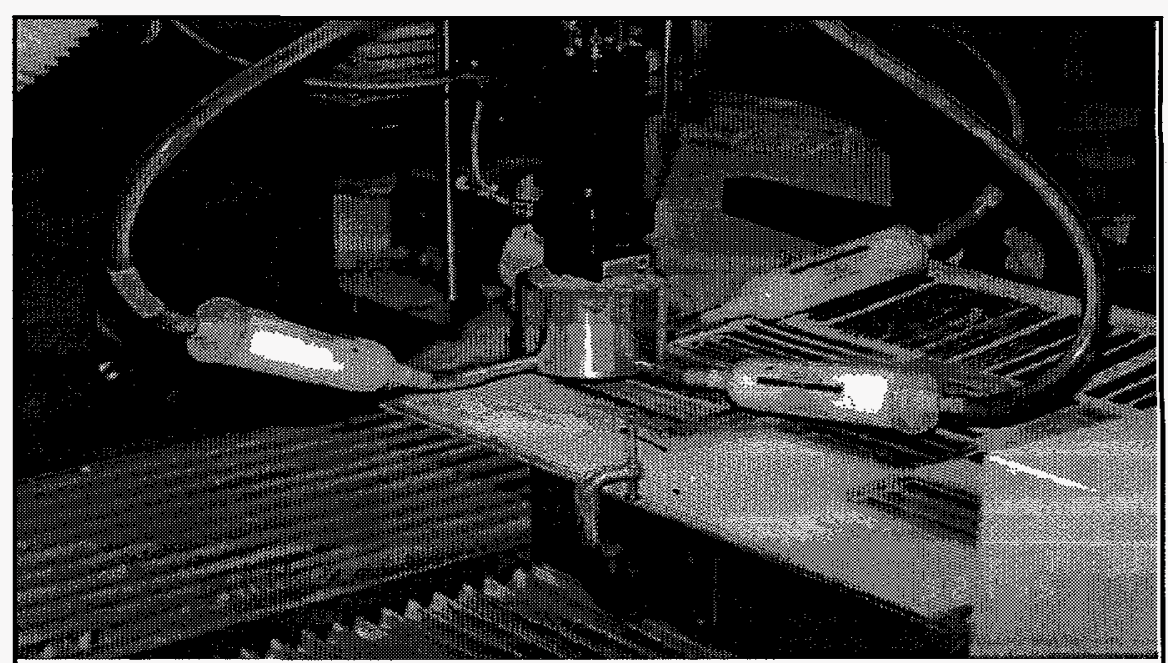

Figure 2. Picture of Nd:YAG laser workstation showing black anodized output optics holder for fiber delivered beam and aluminum shroud where HEPA capsule filters were attached in an experiment to determine the total mass of aerosol particles produced from the laser ablation of painted steel plates. considered to be in the respirable size range. The collection efficiency improves for smaller particles with $>99.99999 \%$ collection of particles $<1 \mu \mathrm{m}$..

Aerosol particle distributions obtained were measurably different between different paint compositions (latex and oil-base). This is illustrated in Figure 3, which shows aerosol impactor data for the two paints. The aerosol produced by the oil-base paint has a substantially larger fraction in the sub-micrometer size range than the latex paint indicating more complete combustion. This was found to be the case for other paint thicknesses. However, for a given paint, fine particle size data obtained with an aerosol spectrometer showed little

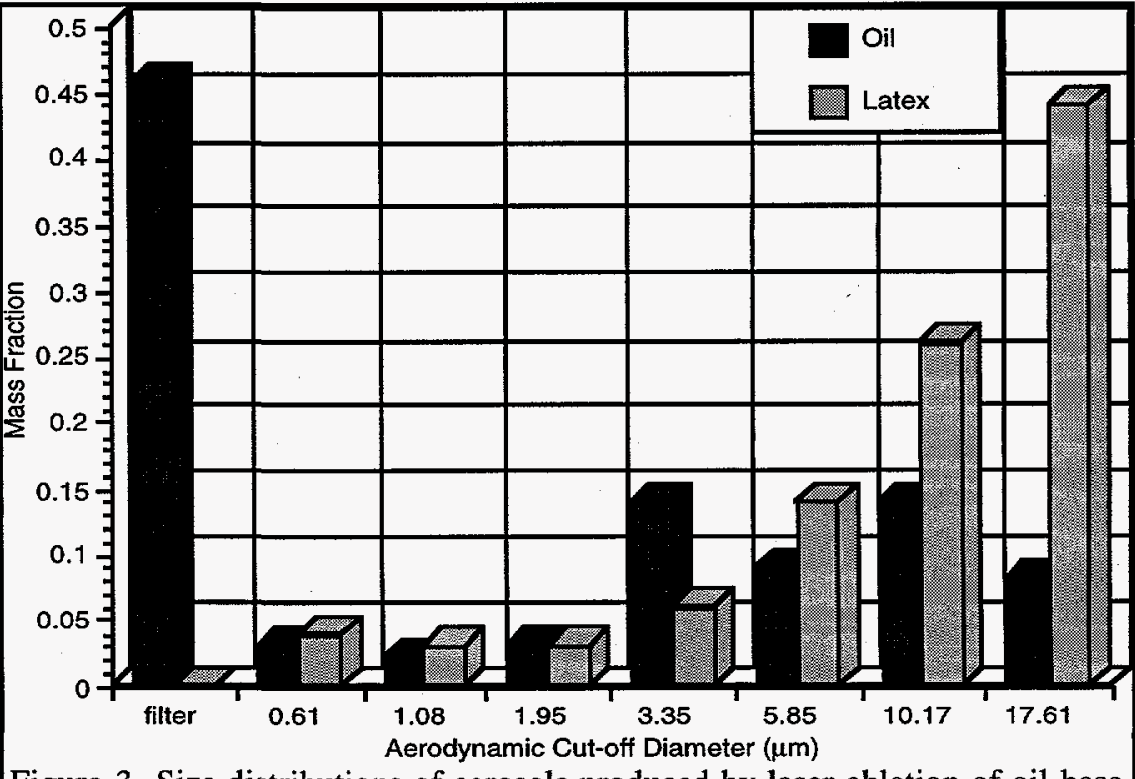

Figure 3. Size distributions of aerosols produced by laser ablation of oil-base and latex paints. The paint thicknesses used were $240 \mu \mathrm{m}$ for the oil-base and $368 \mu \mathrm{m}$ for latex. The character of the size distributions were not affected by paint thickness. sensitivity to representative paint thicknesses $(250-400 \mu \mathrm{m})$. These results indicate that the multiple pulses incident on the paint to effect its removal tend to be a repetitive process for each pulse. 

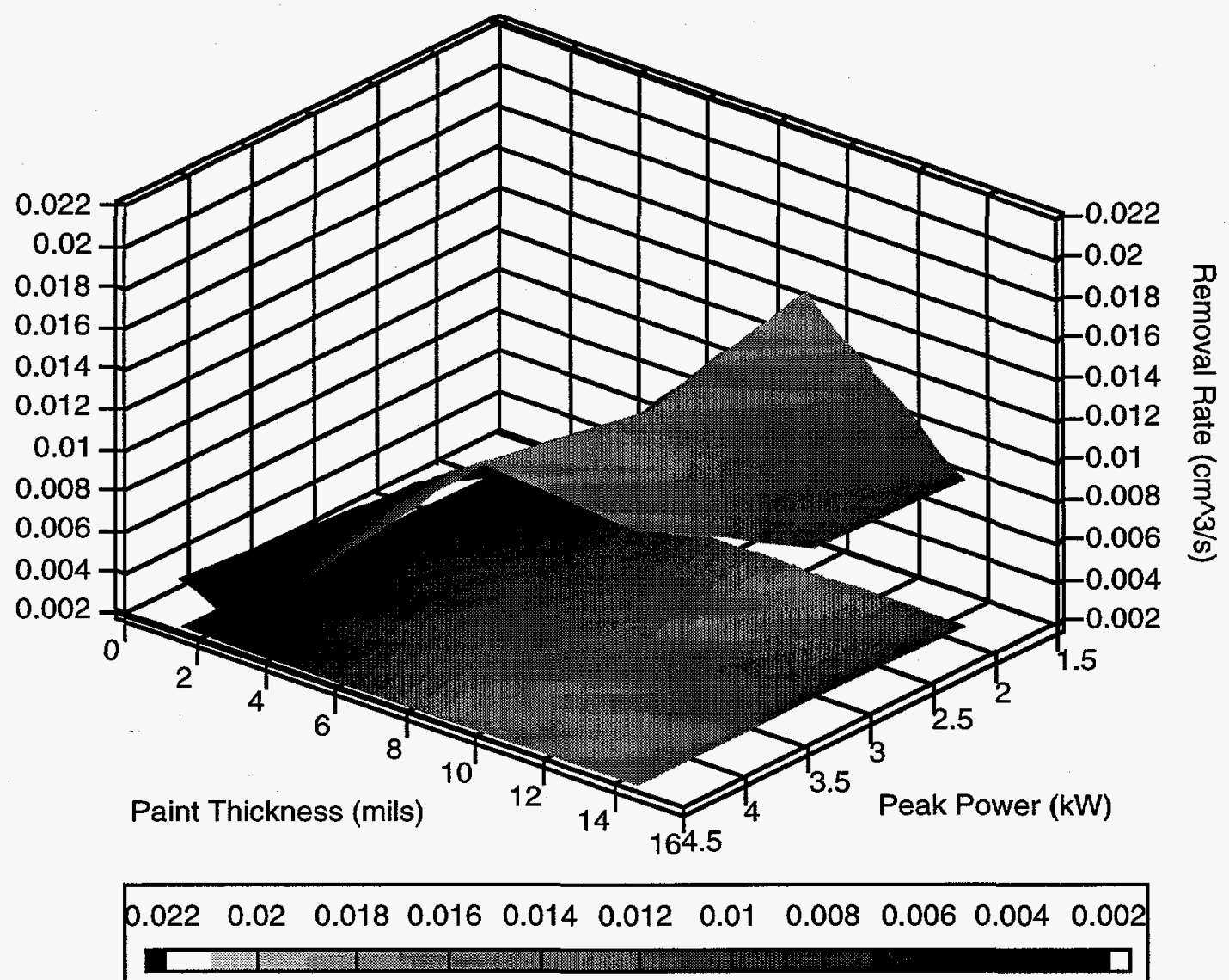

Figure 4. Ablation data for different latex paint thicknesses and pulsed power obtained with a multimode Nd:YAG laser using fiber optic beam delivery. The laser beam average power varied from 730 to $890 \mathrm{~W}$. The irradiance values are $<310^{4} \mathrm{~W} \mathrm{~cm}-3$. The surface plotted displays the fit to the volumetric removal rate data with the lighter greys representing higher values. Each location on the surface accounted for multiple data points, each representing different feed rates and number of repeated passes. The "floor" of the plot is a contour map of the surface above.

The volumetric paint removal rate of all data with the irradiance $<310^{4} \mathrm{~W} \mathrm{~cm}^{-3}$ is plotted in Fig. 4. Volumetric rates were considered more appropriate than surface area because of the thick paint layers (requiring multiple passes) in this application. The data suggest that the selection of laser parameters at low irradiances is driven by paint thickness, rather than peak power or repetition rate. The removal rate is relatively insensitive to peak power level for this average power range; $0.25 \mathrm{~mm}$ (10 mils) is approximately the optimal thickness. Depending on the pulse energy, a paint layer of 0.25 to $0.3 \mathrm{~mm}$ can be removed in a single pass. A second pass is required to remove the soot if the irradiance is low. If the paint is too thin, energy is wasted by heating the metal plate and a low removal rate results. If it is too thick, too little paint is removed and several passes are required to remove the paint, yielding a low rate. The removal rate takes into account the volume of paint removed, the feed rate, and number of passes required to clean the surface effectively. There are several possible reasons for this relative insensitivity to peak power: (1) the range of peak power levels did not vary enough to change the removal mechanism, (2) the process appears to be energy limited, and (3) soot formation forces multiple passes to be made. Tests have indicated that soot formation can be eliminated by a cross-jet; however, containment of effluent is not possible because the high velocity jet blows the aerosol out underneath the shroud. The soot formation can be eliminated at irradiance values above $3 \times 10^{-4} \mathrm{~W} \mathrm{~cm}^{-3}$. For paint thicknesses previously requiring 
two passes for soot removal a doubling of the removal rate resulted. The results in Figure 4 show the need to better understand the effects of using different irradiance levels on the ablation process and the formation of aerosols.

The ablation of a typical sample of high density concrete used in nuclear reactor facilities was also examined using pulsed Nd:YAG lasers. A 350W Lumonics JK702H and an Electrox $1.6 \mathrm{~kW}$ with fiber delivery were used. A airknife was used with the Lumonics laser while a crossjet (air or nitrogen) or a cutting nozzle with coaxial assist gas were used with the Electrox laser. Various paints (quick dry lacquer, epoxy enamel, polyurethane gloss enamel and acrylic) were used on the concrete. A defocussed beam from the Lumonics laser was used to raster over the surface of the painted or unpainted block of concrete. The peak irradiance was approximately $6 \times 10^{3} \mathrm{~W}$ $\mathrm{cm}^{-2}$ with pulses of $2.25 \mathrm{~J}$ and $0.5 \mathrm{~ms}$ at $100 \mathrm{~Hz}$. Travel speeds of 3.2 to $4.2 \mathrm{~cm}$ $\mathrm{s}^{-1}(75$ to $100 \mathrm{ipm})$ were used. For the Electrox laser case, peak irradiance values used were 9x105 W cm-2 and $5 \times 10^{6} \mathrm{~W}$ $\mathrm{cm}^{-2}$ with corresponding $1 \mathrm{~ms} 100 \mathrm{~Hz}$ pulses of $1.8 \mathrm{~J}$ and 10J. Travel speeds of $4 \mathrm{~cm} \mathrm{~s}^{-1}$ and $8 \mathrm{~cm} \mathrm{~s}^{-1}$ were used. The results of the laser ablation on the concrete are shown in Fig. 5. The left side of the concrete was painted while the middle and right sides were unpainted.

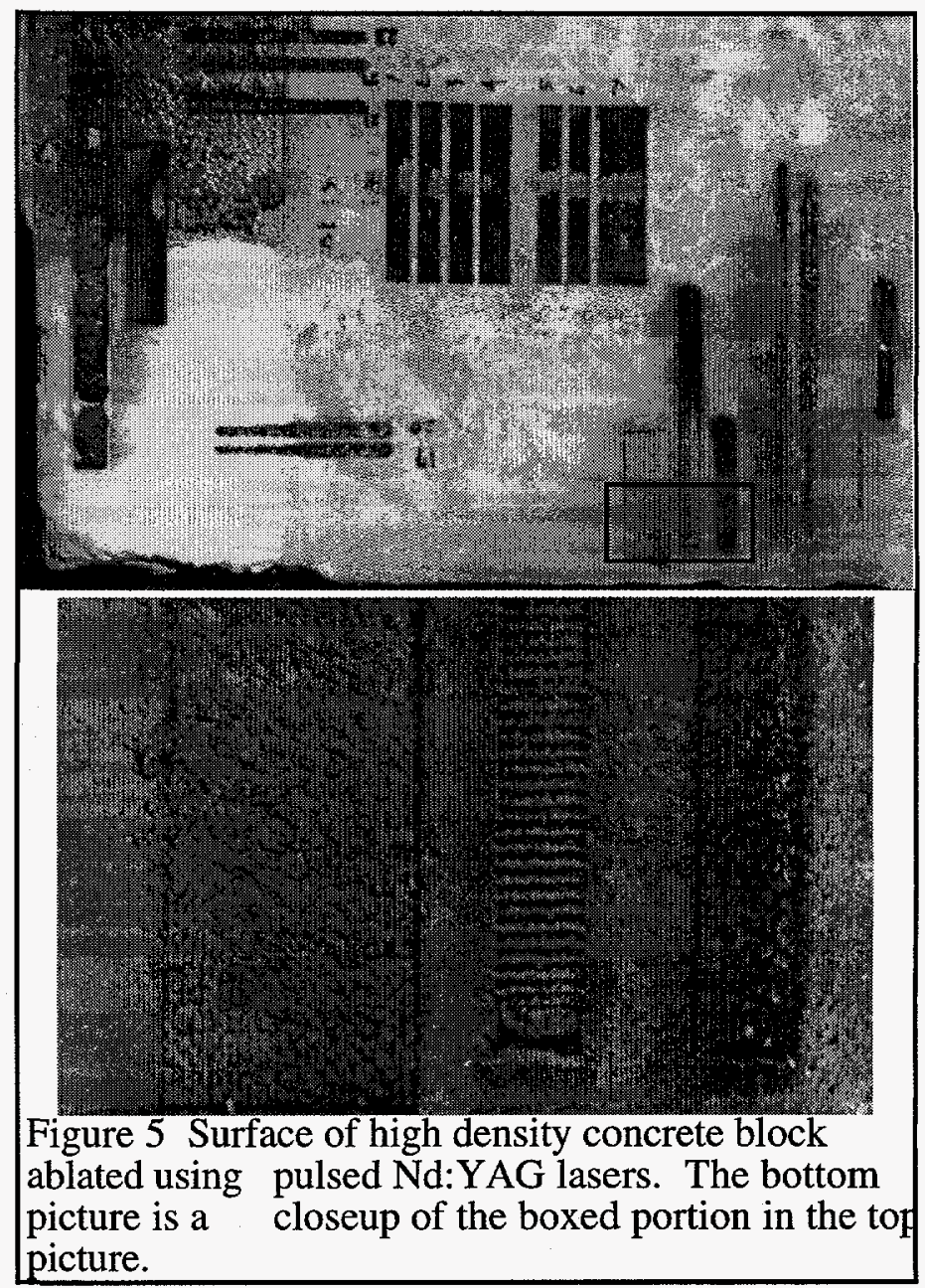

At the low irradiance levels, absorptivity was important and the epoxy enamel on concrete or metal was the easiest to ablate. The polyurethane enamel being mostly transparent was the least ablated. Because the paints had low absorptivity the concrete was also ablated. Ablation paths were created by rastering the beam. The surface was darkened after ablation and showed evidence of melting for the low irradiance cases. Light scraping removed most of the material on the irregular ablated surface and is shown as lighter patches across the (vertical) ablation paths in the middle section of the concrete surface. For the comparable average power cases between the two lasers, the ablation was very similar in depth and appearance. Using air or nitrogen did not appear to affect the substantial aerosol formation. The use of an airknife or crossjet without the cutting nozzle blew away the aerosol and left an ablated and darkened path as shown in the middle section. Using a cutting nozzle resulted in the deposition of the aerosol particles on the concrete forming a brown coating as shown on the left section of the concrete and in the bottom picture. The middle ablation path showed a stitching effect because the speed used caused the pulses not to overlap.

For decontamination, containment of the aerosol produced during ablation is essential. The tests on ablation of painted steel did not produce spatter that would coat the cover glass protecting the focussing optic. Ablation of concrete using air or nitrogen produce large amounts of aerosol and spatter that tend to coat the cover glass rapidly when a cutting nozzle was used. The use of a crossjet or airknife provided more protection but makes the aerosol harder to contain. These 
preliminary results indicate that a special containment and gas assist system is necessary to contain the aerosol produced and to avoid spatter on the output optics so that effective beam delivery can be realized for ablation of large contaminated areas.

\section{Effluent Analysis}

The vapor and fine aerosol particles $(<10 \mu \mathrm{m})$ produced by laser ablation can be captured by a fume containment system. This material is amenable to analysis by on-line techniques such as mass spectrometry; however chemical transport from the solid to the effluent to the instrument needs to be understood. The ablated material consists of elements and compounds with a wide range of volatilities. It is expected that the different size ranges in the aerosol particles will be pre-concentrated with compounds of different volatilities 23-25. For instance, in the case of organic coatings, soot particles form quickly owing to the high abundance and low volatility of carbon. The nascent particles then provide surfaces on which less abundant, more volatile compounds can condense. The partitioning of contaminants between the vapor and solid phases, and the differing condensation rates of various elements may lead to chemical segregation of contaminants across particles of varying size. The extent of this segregation will influence the accuracy of the on-line analysis device. A complete effluent characterization is needed to model the laser-surface and plasma-surface interactions.

On-line analysis could in principle be performed on the plasma itself, via direct emission spectroscopy in the pre-plasma regime 26,27 or laser-induced breakdown spectroscopy of plasmas 28. These techniques would be difficult to implement within the fume containment system, and analyze for contaminants in the plasma rather than in the waste stream. On-line wastestream analysis is challenging in that the effluent is in the form of solid particles, which must somehow be introduced to the analytical instrument. Inductively Coupled Plasma-Mass Spectrometry (ICP-MS) is well suited to the task, and indeed laser ablation - ICP-MS is a viable analytical method for direct trace element determination on solid surfaces, with detection limits ranging from part-per-million to part-per-billion 29-31. Additionally, ICP-MS can discriminate between radioactive and non-radioactive isotopes.

The goal of any solid surface analysis is to ensure that the spectrometer faithfully reports the composition of the surface under investigation. The surface must be vaporized completely, without fractionation based on volatility, and the effluent must be transported efficiently to the spectrometer. The efficiency of vaporization and ionization in an ICP drops off with particle size 32 , so that large or inefficiently transported particles will escape detection. It is therefore important to match the particle size distribution produced by laser ablation to that which the ICP can process efficiently, and to ensure that the particle size transfer function of the sampling system overlaps the response function of the ICP-MS. Thus, the influence of the ablation parameters and sampling system on the overall transfer of contaminants from surface to detector needs to be characterized. To this end it is important to fully characterize test surfaces both before and after ablation, and examine the various regions of the PSD for chemical segregation. It is conceivable that the ablation parameters can be so chosen that the chemical and physical profile of the effluent is amenable to characterization and/or efficient capture. For example, fine particles in the aerodynamic size range of 0.1 to $10 \mu \mathrm{m}$ can be transported through tubing to instruments for analysis without substantial losses, whereas ultrafine particles $<0.1 \mu \mathrm{m}$ are susceptible to diffusional losses and coarse particles $(>10 \mu \mathrm{m})$ suffer inertia losses 33 . Transport and trapping systems for effluent characterization can be designed to optimally sample the different particle size ranges.

\section{$\underline{\text { References }}$}

1. Dickerson, K.S., M.J. Wilson-Nichols and M.I. Morris (1995). Contaminated Concrete: Occurrence and Emerging Technologies for DOE Decontamination, DOE/ORO/2034. 
2. (March 1994). Decommissioning Handbook, U.S. Department of Energy DOE/EM-0142P.

3. Cannon, N. S., and D. J. Flesher (1993). Lasers for the Radioactive Decontamination of Concrete, Westinghouse Hanford Company, WHC-SA-2116-FP.

4. Demmer, R. L. and R. L. Ferguson (1994). Testing and Evaluation of Light Ablation Decontamination, Idaho National Engineering Laboratory, INEL-94/0134.

5. Leong, K. H. and B. V. Hunter (1996). High Power Fiber Optic Laser Beam Delivery Moves Forward, Industrial Laser Review, May 7-12.

6. Foley, J. (1991). Laser Paint Stripping: An Automated Solution. Industrial Laser Review, August, 4-9.

7. (June 1992 and 1993). Laser Removing of Lead-Based Paint, Reports by Midwest Companies to Illinois Department of Transportation.

8. Freiwald, J. and D. A. Freiwald (1995). Laser Surface Cleaning, Proc. Environmental Tech. Through Industry Partnership, Morgantown, WV.

9. Head, J. D. (1991). New $\mathrm{CO}_{2}$ Laser Cuts Paint-Stripping Damage, Industrial Laser Review, August, 11-14.

10. Liu, K. and E. Garmire (1995). Paint Removal Using Lasers, Applied Optics. 34: 4409-4415.

11. Grace, J., K. Leong and B. Hunter (1955).Experimental Study of an Aerosol Collection System for Laser Processes, American Association for Aerosol Research, Annual Meeting, October 9-13, Pittsburgh, Pennsylvania.

12. Ready J. F. (1971). Effects of High-Power Laser Radiation, Academic Press New York

13. Von Allmen, M. and Springer-Verlag (1986). Laser-Beam Interactions with Materials, New York.

14. Phipps, C. R. and R. W. Dreyfus (1993). The High Laser Irradiance Regime, A. Laser Ablation and Plasma Formation, in Laser Ionization Mass Analysis, A. Vertes, R. Gijbels, F. Adams, Editors, John Wiley \& Sons, Inc., New York.

15. Figueira, J. F., S. J. Czuchlewski, C. R. Phipps and S. J. Thomas, Plasma-Breakdown Retropulse Isolators for the Infrared. Appl. Opt., 20: 838-841.

16. Sappey, A. D. and N. S. Nogar (1994). Diagnostic Studies of Laser Ablation for Chemical Analysis, in Laser Ablation: Principles and Applications. J. C. Miller, Editor, Springer-Verlag, Berlin

17. Sappey, A. D. and T. K. Gamble (1992). Planar Laser-Induced Fluorescence Imaging Of Cu Atom and $\mathrm{Cu}_{2}$ In A Condensing Laser-Ablated Plasma Plume. J. Appl. Phys., 72(11), 5095-5107

18. Nogar, N.S., R.C. Dye, R.C. Estler, S.R. Foltyn, R.E. Muenchausen, and X.D. Wu (1991). Diagnostic Studies of $\mathrm{Yba}(2) \mathrm{Cu}(3) \mathrm{O}(7 \partial)$ in Laser Ablation Mechanisms and Applications, J.C. Miller and R.F. Halund, Eds., Springer-Verlag, Berlin, 3-11. 
19. Kokosa, J. M. and M. D. Benedetto (1992). Probing Plume Protection Problems in the Health Care Environment. J. Laser Applications. 4, 39-43.

20. Kokosa, J. M. (1994). J. Laser Hazardous Chemicals Produced by Laser Materials Processing. J. Laser Appl. 6: 195-201.

21. Haferkamp, H., J. S. Wittbecker and A. Hampe (1992). Characterization of Emissions Resulting from Laser Material Processing and Exhaust Air Cleaning. Aerosol Sci. 25, 5823-26.

22. Haferkamp, H., K. Engel, M. Goede and T. Püster (1994). Characterization of Emissions Generated during Laser Material Processing and Emission Formation Process. Aerosol Sci. 25: S37-8 .

23. Bierman, A.H. and J.M. Ondov (1980). Application of surface-deposition models to size-fractionated coal fly ash, Atmos. Environ. 14:289-295.

24. Natusch, D.F.S., J.R. Wallace and C.A. Evans, Jr. (1974). Toxic Trace ELements: Preferential Concentration in Respirable Particles, Sci. 183:202-20.

25. Smith, R.D., J.A. Campbell, and K.K. Nielson (1979). Concentration Dependence upon Particle Size of Volatized elements in Fly Ash, Environ. Sci. Technol. 13:553-558 .

26. Moenke, H. and L. Moenke-Blankenburg (1973). Laser Micro-Spectrochemical Analysis, Crane, Russak, and Co., New York.

27. Cremers, D. A. and L. J. Radziemski (1987). Laser Plasmas for Chemical Analysis, in Laser Spectroscopy and its Applications, R. W. Solarz and Paisner, J. A., Editors, Marcel Dekker, New York.

28. Cremers, D. A. (1987), The Analysis of Metals at a Distance Using Laser-Induced Breakdown Spectroscopy. Appl. Spectr. 41: 572-579.

29. Denoyer, E R. K. J. Fredeen and Hager, J. W. (1991) Laser Solid Sampling for Inductively Coupled Plasma Mass Spectrometry. Anal. Chem. 63, 445A-457A.

30. Moenke-Blankenburg, L. ( 1993). The High Laser Irradiance Regime, B. Solid Sampling for Analysis by Laser Ablation, in Laser Ionization Mass Analysis, A. Vertes, R. Gijbels, F. Adams, Editors, John Wiley \& Sons, Inc., New York.

31. Brenner, I. B. and H. E. Taylor (1992). A Critical Review Of Inductively Coupled Plasma Mass Spectrometry For Geoanalysis, Geochemistry, And Hydrology. Part I. Analytical Performance, Crit.Rev. Anal. Chem. 23, 355-367

32. Arrowsmith, P. (1990). Applications of Laser Ablation: Elemental Analysis of Solids by Secondary Plasma Source Mass Spectrometry, in Lasers and Mass Spectrometry, D. M. Lubman, Editor, Oxford University Press, New York.

33. Hinds, W. C. (1982). Aerosol Technology, Properties, Behavior, and Measurement of Airborne Particles, Wiley-Interscience, New York. 